\title{
ROLE OF THE CULTURAL CONTEXT IN DETERMINING THE USE OF PATIENT SAFETY; A MIX METHOD STUDY
}

\author{
Najm Us Saqib Khan, Assad Hafeez*, Rehana Khadim**, Anam Haider**, Aliya Hisam**, Tahir Mahmood Butt*** \\ Bahria University Medical \& Dental College, Karachi Pakistan, *Health Services Academy, Islamabad Pakistan, **Army Medical College/National University of \\ Medical Sciences (NUMS) Rawalpindi Pakistan, ${ }^{* * * S i a l k o t ~ M e d i c a l ~ C o l l e g e, ~ S i a l k o t ~ P a k i s t a n ~}$
}

\section{ABSTRACT}

Objective: To compare the role of the cultural context in determining the use of patient safety by participants from private and public sector hospitals of Karachi, Pakistan.

Study Design: Mix method study.

Place and Duration of Study: In two tertiary care hospitals (one private and one public sector) of Karachi, from Nov 2016 to Nov 2017.

Methodology: A sample size of 153 was enrolled by consecutive convenient sampling technique. The role of the cultural context of both hospitals was compared by asking questions from the hospital's staff. Data were collected by the researcher using an open and closed-ended questionnaire.

Results: Data of 153 successful and filled questionnaires were analyzed. Out of 153, 78 (51\%) cases were for private hospitals and $75(49 \%)$ cases were for public hospitals. The role of the cultural context in determining the use of the patient safety concept was not sufficiently understood by participants of both hospitals, and most of the participants gave vague answers.

Conclusion: Cultural context is one of the key factors in patient safety as with collective mindfulness about safety issues, and health care can be delivered safely.

Keywords: Cultural context, Health care professional, Patient safety.

How to Cite This Article: Khan NS, Hafeez A, Khadim R, Haider A, Hisam A, Butt TM. Role of The Cultural Context in Determining the Use of Patient Safety; A Mix Method Study. Pak Armed Forces Med J 2021; 71(5): 1577-1581. ～doi: https://doi.org/10.51253/pafmj.v71i5.7350

This is an Open Access article distributed under the terms of the Creative Commons Attribution License (https://creativecommons.org/licenses/by-nc/4.0/), which permits unrestricted use, distribution, and reproduction in any medium provided the original work is properly cited.

\section{INTRODUCTION}

A culture can be defined as "association with the ethnic or racial group, as well as language, thoughts and communications, customs, beliefs and values." Health care is defined via a cultural lens for both patients and professionals. ${ }^{1}$ This can affect where and how people seek medical attention, how they report their symptoms, what treatments they choose and whether or not they follow through on care recommendations. Physicians carry their own culture, especially the culture of medicine with them, in a similar fashion. ${ }^{2}$ Health care systems' cultural competence is defined as their ability to care for patients with a wide range of cultural values, beliefs and behaviours. This includes adapting healthcare delivery to fit patients' social and cultural needs. It is necessary to have behaviours, attitudes and policies that facilitate productive interactions in cross-cultural circumstances to have culturally competent health system. ${ }^{3}$

Cultural competence interventions such as provider training and practical tools are based on a variety of cultural competence models. ${ }^{4}$ Culture and

Correspondence: Dr Najm Us Saqib Khan, Bahria University Medical \& Dental College, Karachi Pakistan

Received: 02 Sep 2021; revision received: 23 Sep 2021; accepted: 01 Oct 2021 language of racial and ethnic minorities have been referred to as cultural competency, but it is increasingly being used to embrace other groups, such as individuals with disabilities. This group of people has been the focus of many studies on cultural competency treatments in recent years. 5,6

Culture and health literacy have become intertwined, recognizing that mutual understanding between patients and providers needs for the combination of culturally and linguistically competent and health literacy-based methods. The new National Standards for Culturally and Linguistically Appropriate Services (CLAS) in Health and Health Care reflect this expansion of cultural competency.7,8

When racial and ethnic disparities in healthcare became more prominent, the cultural competence movement took off. Health and healthcare discrepancies between minority and majority populations have been repeatedly documented in research. There are several minority-majority states, and once homogenous regions have become more diverse, which has strengthened the necessity for cultural competence in health care. 9,10

This study was aimed to compare the role of the cultural context in determining the use of patient 
safety by participants from private and public sector hospitals of Karachi, Pakistan.

\section{METHODOLOGY}

It was a mix method study carried out in two tertiary care hospitals: The Indus Hospital was the Private sector hospital and public sector hospital was Pakistan Navy Ship Shifa (PNS Shifa) of Karachi. The study duration was one year from November, 2016 till November, 2017. The sample size was calculated to be approximately 153. Consecutive sampling technique was used.

Inclusion Criteria: The study population consisted of managerial, physician, and nursing staff of tertiary care hospital of both private and public hospitals.

Exclusion Criteria: Any person who does not wanted to be interviewed was excluded from the study.

Data were collected by the researcher using open and closed ended questionnaire. Confidentiality of the participants was maintained. Participants were asked about the Cultural Context at different elements. Ethical Committee approval was taken and from every patient informed verbal consent was taken. Study was aimed to compare the role of the cultural context in determining the use of patient safety by participants from private and public sector hospitals of Karachi, Pakistan. Considerations for human welfare and rights of participants were kept in mind throughout the research. Written informed consent was obtained from all study participants after explaining the objectives of the study. Participants were informed that they can withdraw from the study at any point without any harm and that their information will be kept confidential. Study participants were also informed that there is no harm in this study as it was a non-invasive study, and 15-20 minutes would be required for conducting interviews.

Data were entered and analyzed using Statistical package for Social Sciences (SPSS) version 20. Categorical variables were summarized in the form of frequencies and percentages while quantitative statistics were summarized as mean and standard deviation. For qualitative analysis, first review was done and data was explored. Initial codes were created, followed by reviewing of those codes, revision and combining into the themes. Themes were presented in a cohesive manner.

\section{RESULTS}

Data of 153 successful and filled questionnaires were analyzed. Out of $153,78(51 \%)$ cases were for private hospitals and 75 (49\%) cases were for public hospitals. The role of the cultural context in determining the use of the patient safety concept was not sufficiently understood by participants of both hospitals, and most of the participants gave vague answers. From the Public hospital, 13 participants gave relevant answers (detailed shown in Table-I).

Table-I: Role of the cultural context in determining the use of patient safety concept by participants from a public hospital.

\begin{tabular}{c|l}
\hline S. No. & What role does cultural context play in determining the use of patient safety concepts in your hospital? \\
\hline 1. & $\begin{array}{l}\text { Yes, cultural context is important not only in a Private hospital but in any reputed organization. This promotes the rate } \\
\text { of patient safety, and hence hazards decrease with time. }\end{array}$ \\
\hline 2. & Developing a culture of safety is one of the core elements for improving patient safety. \\
\hline 3. & $\begin{array}{l}\text { Patient safety is only possible with coordinated efforts of all resources in the healthcare system. So patient safety culture } \\
\text { has a very important role in bringing these efforts closer, and only then patient safety can be ensured if all factors } \\
\text { involved in that culture work in harmony. }\end{array}$ \\
\hline 4. & $\begin{array}{l}\text { Promoting cultural norms that tie within the parameters of better healthcare and avoid cultural concepts and explain the } \\
\text { consequences. }\end{array}$ \\
\hline 5. & Holds the cure rate high, maintain health standards, and minimize the infection spread rate. \\
\hline 6. & $\begin{array}{l}\text { To inform patients and attendants about possible complications of a treatment or procedure to take informed consent } \\
\text { trying to help the patient while avoiding the harm. }\end{array}$ \\
\hline 7. & $\begin{array}{l}\text { Always keep patients and concerned relatives informed. Do take informed consent; keep their religious and cultural } \\
\text { beliefs into consideration. }\end{array}$ \\
\hline 8. & Coordination plays an important role in patient safety. \\
\hline 9. & $\begin{array}{l}\text { Attitudes and behaviors towards admitting that a medical error has occurred discourage healthcare professionals from } \\
\text { learning about how to prevent future adverse incidents. Organizations can promote a proactive approach to ensure safe } \\
\text { patient care. }\end{array}$ \\
\hline 10. & The culture of safety enhances the morale of patients and staff because both will be safe from harm/diseases. \\
\hline 11. & Role modelling at all levels motivates others by seeing and understanding the protocols being used. \\
\hline 12. & Culture implementation is necessary for patient safety as we learn from seniors, elders, and management. \\
\hline 13. & $\begin{array}{l}\text { Communication barriers, language barriers, non-compliance with prescription due to some cultural beliefs, e.g., blood } \\
\text { transfusion, etc. }\end{array}$ \\
\hline
\end{tabular}


Questions regarding cultural context were more poorly responded; due to lack of understanding of the role of culture, from Private hospital as only 7 participants gave relevant answers (Table-II): Regarding knowledge and understanding of patient safety concepts, participants of Public hospitals were more knowledgeable than participants of Private hospital. The three best responses regarding patient safety from Public hospitals were:
The three best responses from Private hospitals were as follows:

1. "Patient safety would include simplest to most complex things like safety in procedures, including verbal/written consent. Orientation to the hospital environment and working staff. Qualified and welltrained staff in the delivery of care, both involved in direct or indirect care".

Table-II: Role of the cultural context in determining the use of patient safety concept by participating from a private hospital.

\begin{tabular}{c|l}
\hline S. No. & What role does cultural context play in determining the use of patient safety concepts in your hospital? \\
\hline 1. & The culture should be set and followed according to the hospital. \\
\hline 2. & It plays a very important role as we have patients from all cultures. \\
\hline 3. & $\begin{array}{l}\text { Patients and families need to be taught many things on the community level. Their education and knowledge can play a } \\
\text { significant role in making their hospitalization safe and harmless. }\end{array}$ \\
\hline 4. & People need to be well educated and well aware of all the safety risks while staying in a hospital. \\
\hline 5. & Culture plays an important role in awareness of religious beliefs. \\
\hline 6. & $\begin{array}{l}\text { Culture plays a vital role in patient safety. Language, cultural beliefs, and awareness of religious beliefs are well } \\
\text { addressed in our hospital. There are a mosque and a mortuary in our hospital for funereal activities. }\end{array}$ \\
\hline 7. & The patient should be well informed, well aware of all the safety issues before admitting. \\
\hline
\end{tabular}

1. "This safety includes the patient to be a safeguard from physical hazards, i.e., his bed is safe, there is no danger of any hanging item like ceiling fan, etc. to be thrown on the patient. No electric switchboard may adversely affect his bed. Instruments/ equipment used must be sterilized. Nursing staff must be well trained and skilled to avoid double pricks. Lab investigations shall be done according to standard protocols".

2. "A clean and safe environment shall be provided for the treatment of patients with minimal risk of infections and harm. The equipment shall be well maintained and be used at the right time and in the right way. Medicines shall be administered in timely and incorrect doses. Care shall be provided in a harmonized way by competent physicians and staff".

3. "Patient safety is protecting patients from medical errors, injuries, accidents, infections, and keeping them comfortable both physically and mentally by using all healthcare resources in the best possible way, whether human resources, medicines or equipment."

Most of the participants from the Public hospital had sufficient good knowledge regarding patient safety and gave more comprehensive and elaborative answers, including almost all aspects related to patient safety. Participants of Private hospitals had average knowledge about patient safety; especially, management staff had low knowledge about patient safety.
2. "Patient safety is connected to several internal and external factors. It can be said that patient safety is related to or have a very close relationship with patient health and cure".

3. "Patient safety means that patients shall not be harmed by any means. Patient safety also includes the protection from errors, injuries, accidents, and infections within the hospital".

\section{DISCUSSION}

Cultural context is one of the key factors in patient safety as with collective mindfulness about safety issues, and health care can be delivered safely. In the present study, the role of the cultural context in determining the use and implementation of the patient safety concept was not sufficiently understood by participants of the public as well as private hospitals. In the present study, the role of physicians and surgeons in the development and promotion of patient safety construct was more clearly defined by study participants of Public hospitals as compared to private hospitals.

Patient safety is not immune to healthcare disparities. When adverse events occur, patients with inadequate language proficiency are more likely to be harmed than their language-proficient counterparts, and the injury is more likely to be serious. As an example, a recent study indicated that hospitalized Latino children are more likely to suffer an unfavourable event than non-Latino white children who are not Latinos. ${ }^{11}$ Diagnostics errors, missed screenings, 
unexpected negative reactions to medication, harmful treatment interactions from simultaneous use of traditional medicines, healthcare-associated infections, adverse birth outcomes, inappropriate care transitions, and inadequate patient adherence are just a few of the patient safety events that can result from failing to address culture, language, and health literacy. ${ }^{12} \mathrm{Un}$ awareness of the fact that a hospitalized Asian woman would only converse with her male family members slowed down the process of obtaining authorization for a required procedure. There is a greater danger of missed care opportunities and safety incidents as the patient population in the United States becomes more diverse. ${ }^{13}$

Along with reducing medical errors and harms, cultural competence can have a significant impact on patient involvement, another important factor in patient safety. When it comes to promoting good communication with patients from different backgrounds, techniques such as language support and the employment of cultural brokers can help. A cultural competence-training programme can help physicians better comprehend what the patient is going through, provide them with the skills to bridge cultural barriers, and build trust. ${ }^{14}$

Using a cultural broker could be one way to improve cultural competency in healthcare, according to the authors. It is the act of mediating between a patient's cultural health beliefs and practices and the healthcare system. By giving context and working as a partner for both the patient and the physician, interpreters, community health workers, and patient navigators can act as cultural brokers. A cultural broker's function varies depending on patient and provider needs, but they must have a thorough understanding of the culture they serve and be able to successfully navigate the healthcare system. Cultural brokers should be trusted and respected members of the community, but they do not have to be health care experts to execute their job effectively. It is important to recognize the importance of cultural distinctions among patient groups by including a cultural broker in the treatment team. There is also an acknowledgement of the fact that it is unrealistic for physicians, especially in highly varied settings, to have a complete awareness of all of their patients' cultures and customs. ${ }^{15,16}$

A cultural competence-training programme should aim to develop cultural awareness and knowledge as well as skills, abilities, resulting in a shift in behaviours and attitudes. Studies on cultural competence training have generally concluded that it improves provider results, but that training alone may not be enough to enhance patient outcomes without concurrent systemic and organizational improvements as well. ${ }^{17,18}$

For hospitals to improve their discharge process, researchers at Boston University Medical Center developed a list of 12 tasks they should follow during and after a patient's stay. Other recommendations include recruiting bilingual and bicultural discharge educators, giving cultural and linguistic competence training, as well as ensuring interpretation services is available. It also explains how each component may need to be changed for different patient groups ${ }^{18}$.

\section{CONCLUSION}

Cultural context is one of the key factors in patient safety as with collective mindfulness about safety issues, and health care can be delivered safely.

\section{Conflict of Interest: None.}

\section{Authors' Contribution}

NSK: Principal investigator. AH: Intellectual contribution. RK: Intellectual contribution. AH: Intellectual contribution. AH: Intellectual contribution. TMB: Intellectual contribution.

\section{REFERENCES}

1. Archer S. Development of a theoretical framework of factors affecting patient safety incident reporting: a theoretical review of the literature. BMJ Open 2017; 7(12): e017155.

2. World Health Organization and World Alliance for Patient Safety. Summary of the Evidence on Patient Safety: Implications for Research. Geneva: World Health Organization and World Alliance for Patient Safety; 2009 [Internet] Available from: https://apps.who.int/iris/ handle/10665/43874. (Accessed July 15, 2020).

3. Barach P, Small SD. Reporting and preventing medical mishaps: lessons from non-medical near miss reporting systems. BMJ 2000; 320(7237): 759-763.

4. Noble DJ, Pronovost PJ. Underreporting of patient safety incidents reduces health care's ability to quantify and accurately measure harm reduction. J Patient Saf 2010; 6(4): 247-50.

5. Mahran SM, Ibrahim SAEA. Patient safety culture and application of medication safety rules as perceived by nurses. Am J Nurs Sci 2016; 5(2): 52-58.

6. Eddy K, Jordan Z, Stephenson M. Health professionals' experience of teamwork education in acute hospital settings: a systematic review of qualitative literature. JBI Database System Rev Implement Rep 2016; 14(4): 96-137.

7. Kristensen S. Strengthening leadership as a catalyst for enhanced patient safety culture: a repeated cross-sectional experimental study. BMJ Open 2015; 6(2): e010180.

8. Wami SD, Demssie AF, Wassie MM, Ahmed AN. Patient safety culture and associated factors: a quantitative and qualitative study of healthcare workers' view in Jimma zone Hospitals, Southwest Ethiopia. BMC Health Serv Res 2016; 16(2): 495-505.

9. Simsekler M, Ward JR. Design for patient safety: a systems-based risk identification framework. Ergonomic 2018; 61(8): 1046-1064. 


\section{Cultural Context Role in Patient Safety}

10. Verbakel NJ, Langelaan M, Verheij TJ, Wagner C, Zwart DL. Improving patient safety culture in primary care: a systematic review. J Patient Saf 2016; 12(3): 152-158.

11. Wagner C. Unit-based incident reporting and root cause analysis: variation at three hospital unit types. BMJ Open 2016; 6(6): e011277.

12. Zwijnenberg NC. Healthcare professionals' views on the feedback of a patient safety culture assessment. BMC Health Services Res 2016; 16(2): 199-205.

13. Dana-Farber Cancer Institute. Patient Safety Round Team Survey. [Internet] Available from: http://www.dana-farber.org/ uploadedFiles/Library/adultcare/care-quality-and-safety/ patient-safety-resources/patient-safetyrounding-toolkit/staffsurvey.pdf (Accessed August 30, 2020).

14. Verbeek-van Noord I. A nation-wide transition in patient safety culture: a multilevel analysis on two cross-sectional surveys. Int J Qual Health Care 2019; 31(8): 627-632
15. Sorra J, Nieva V. Hospital survey on patient safety culture. (Prepared by Westat, under contract no. 290-96-0004). AHRQ publication no. 04-0041. 2004; Rockville: [Internet] Available: http://www.ahrq.gov/professionals/qualitypatientsafety/patie ntsafetyculture/hospital/index.html. (Accessed Jul 15 2020).

16. Hefner JL, Hilligoss B, Knupp A, Bournique J, Sullivan J, Adkins E, et al. Cultural transformation after implementation of a crew resource management: is it really possible. Am J Med Qual 2017; 32(4): 384-90.

17. Lee SH, Phan PH, Dorman T, Weaver SJ, Pronovost PJ. Handoffs, safety culture, and practices: evidence from the hospital survey on patient safety culture. BMC Health Serv Res 2016; 16(1): 254-60.

18. Kiaei MZ, Ziaee A, Mohebbifar R, Khoshtarkib H, Ghanati E, Ahmadzadeh A, et al. Patient safety culture in teaching hospitals in Iran: assessment by the hospital survey on patient safety culture (HSOPSC). J Health Man Info 2016; 3(2): 51-56. 